\title{
The ARt of Inequality: A Proposed Youth Social Justice Exhibition in Augmented Reality
}

\author{
Anisa Bora \\ Teachers College, Columbia University \\ Grace Choi \\ Teachers College, Columbia University \\ Thomonique Moore \\ Teachers College, Columbia University \\ Rongwei Tang \\ Teachers College, Columbia University \\ Claire Yiming Zheng \\ Teachers College, Columbia University
}

Activist art is profoundly involved in politics and social reform (Weibel, 2015). Artistic practice can help increase people's awareness of critical social issues (Adams, 2001), and motivate them to respond and alter their perspectives and perceptions of the environment (Ryan, 2015). The development of digital technologies also provides new opportunities for digital arts. Utilizing technologies as humanizing tools harnesses creation, expression, and interaction (Blikstein, 2008). A core principle of the museum as a public educational institution in a democratic society is to achieve greater inclusion and represent the nation's diversity (Moorhouse et al., 2019). However, museums as cultural institutions have long been silent on their origins (Edwards et al., 2006) and complicity ( $\mathrm{Ng}$ et al., 2017) in establishing imperialist, colonialist, and oppressive principles. Furthermore, a digital divide (Bower et al., 2014) is exhibited in disparities in access to and proficiency in creative uses of digital technologies. Thus, there is an existing racial and socioeconomic gap in (digital) art, activism education, and museum curation. While museums and heritage sites have adopted the use of augmented reality (AR) for educational and exhibitionary purposes by offering immersive learning opportunities for school children (Moorhouse et al., 2019; Srikanth, 2021), none of this previous work directly addresses honing criticality in student voices and creation in the white cube setting using digital technologies in an explicit manner. Whose stories are told in museum collections, and whose are not? We believe that in fostering students' digital creation process as well as their questioning of dominant narratives, youth can be equipped to externalize dissent and reclaim institutional spaces for their communities.

As such, we raise the question: How can youth be empowered by digital technology as a channel of art activism to address issues pertinent to them and their communities that are not historically addressed in museum spaces?

In response to this question, we introduce The ARt of Inequality, a proposed 15-week long curriculum for high-school-aged youth from minoritized backgrounds that combines social justice and art-activism via the development of digital AR pieces. We drew inspiration from the teen education programs at the Noguchi Museum in New York City, 
in which local high school students participate in workshops on digital platforms, collaborative creation, and community outreach. This particular museum's efforts to make local student voices heard challenged us to think about ways to connect resources made available by cultural institutions throughout the United States to the youth in their surrounding communities.

We draw heavily from Paulo Freire's seminal work Pedagogy of the Oppressed in the development of our proposed curriculum to encourage and challenge students to view education as a practice of freedom and to actively participate in the world not as a static reality, but one that is constantly shifting alongside their sense of place and identity (Freire, 2005; Thanapornsangsuth \& Holbert, 2020). We specifically integrate AR as a storytelling instrument through which students are empowered to implement their transformation of self and surroundings by way of making (Blikstein, 2008; Papert, 1988; Srikanth, 2021). We consider AR creation to align with Papert's theory of constructionism states that learners develop their understanding of the world by creating an artifact outside of themselves (Papert, 1988). Through AR construction, students are purposely positioned as critical designers (Bower et al., 2014; Holbert et al., 2020) who bring their own ideas, beliefs, and critiques of the world into reality through the use of technology. In line with Freire's notion of generative themes (Freire, 2005), our proposed curriculum takes students through researching social justice issues based on their lived experiences and ultimately creating their AR interventions through construction and media-making as a means of critique.

Our proposed curriculum (see Figure 1), broken down into four units, would effectively guide students through the aforementioned digital creation process while also supporting them as they simultaneously challenge oppressive narratives and reclaim institutional spaces, namely museums, for themselves and their communities. Unit 1 aims to provide students with an introduction to and a foundational understanding of the role that art plays in activism. Students learn to contextualize the impact and role that art can have on social justice movements that resonate or are personally relevant to them via a combination of activities, including lectures, digital media-making assignments, and a speaker series that invites local artists and activists to provide insights and additional mentorship to students. Unit 2 invites students to think about the history and purpose of museums critically. In Unit 3, students integrate their critical analysis of museum narratives and incorporate poignant generative themes (Blikstein, 2008; Freire, 2005) they have identified for themselves into a final digital AR piece. In Unit 4, students showcase their work at a designated partner museum and exhibition site. Throughout the curriculum, mentors guide students based in their communities as they establish their own understanding of the partnering museum's existing works, how the space functions and for whom. Upon completing the program, students can exit with the knowledge and skills to further engage in forms of digital art activism moving forward, thus enabling them to continue designing their own interventions and assert previously unseen narratives. 
Figure 1

Curriculum Overview

\section{THE ART OF INEQUALITY: A YOUTH SOCIAL JUSTICE EXHIBITION CURRICULUM DESIGN}

\author{
UNIT 01: \\ Contextualization
}

\author{
UNIT 02: \\ Rethinking the Museum
}

UNIT 03:

Media-Making \& Artifact Construction

UNIT 04:

Exhibition \& Assessment
WEEK 1: What is Art Activism?

WEEK 2: Digital Media Workshop

WEEK 3: Speakers Series

WEEK 4: What Defines a Museum? Part I

WEEK 5: Reflection, Site Visit \#2

WEEK 6: Reflection, Site Visit \#3

WEEK 7: What Defines a Museum? Part II \&

Concept Brainstorm

WEEK 8: Intro to Creating Art for AR Part I

WEEK 9: Intro to Creating Art for AR Part II

WEEK 10: Project Definition \& Ideation

WEEK 11: Prototype Development Week 1

WEEK 12: Prototype Development Week 2

WEEK 13*: Prototype Development Week 3 WEEK 13/14: Testing \& Exhibition Prep

*OPTIONAL

WEEK 13/14: Exhibition opening

WEEK 14/15: Post-Production \& Reflection

To illustrate the potential of the curriculum for empowering youth, we developed a prototype of a student project (see Figures 3 and 4) that incorporates an artwork titled Home, Sweet Home (1931) by American painter Charles Sheeler (see Figure 2). This painting, along with others by the artist collectively known as the American Interiors series, showcases a collection of what are considered American artifacts or Americana inside the artist's home (Wilson, 2011). A high school student living in Detroit, Michigan (where the painting is part of a museum collection) who identifies as a child of immigrants might incorporate this artwork into their final project as a way to critique what is/has been depicted as American by overlaying on top of the painting a video clip featuring the sights and sounds of fireworks as well as photos of objects from their own home connected to 
their cultural background that might be perceived as 'other'. When the painting is viewed using the AR tool, viewers would revisit the definition of Americana through the lens of a first-generation American youth. In this example, this student would have the opportunity to present a non-dominant narrative in the form of critique of American life in a space traditionally preserved for dominant cultures, thereby reclaiming an institutional space.

\section{Figure 2}

Home, Sweet Home (1931) by Charles Sheeler

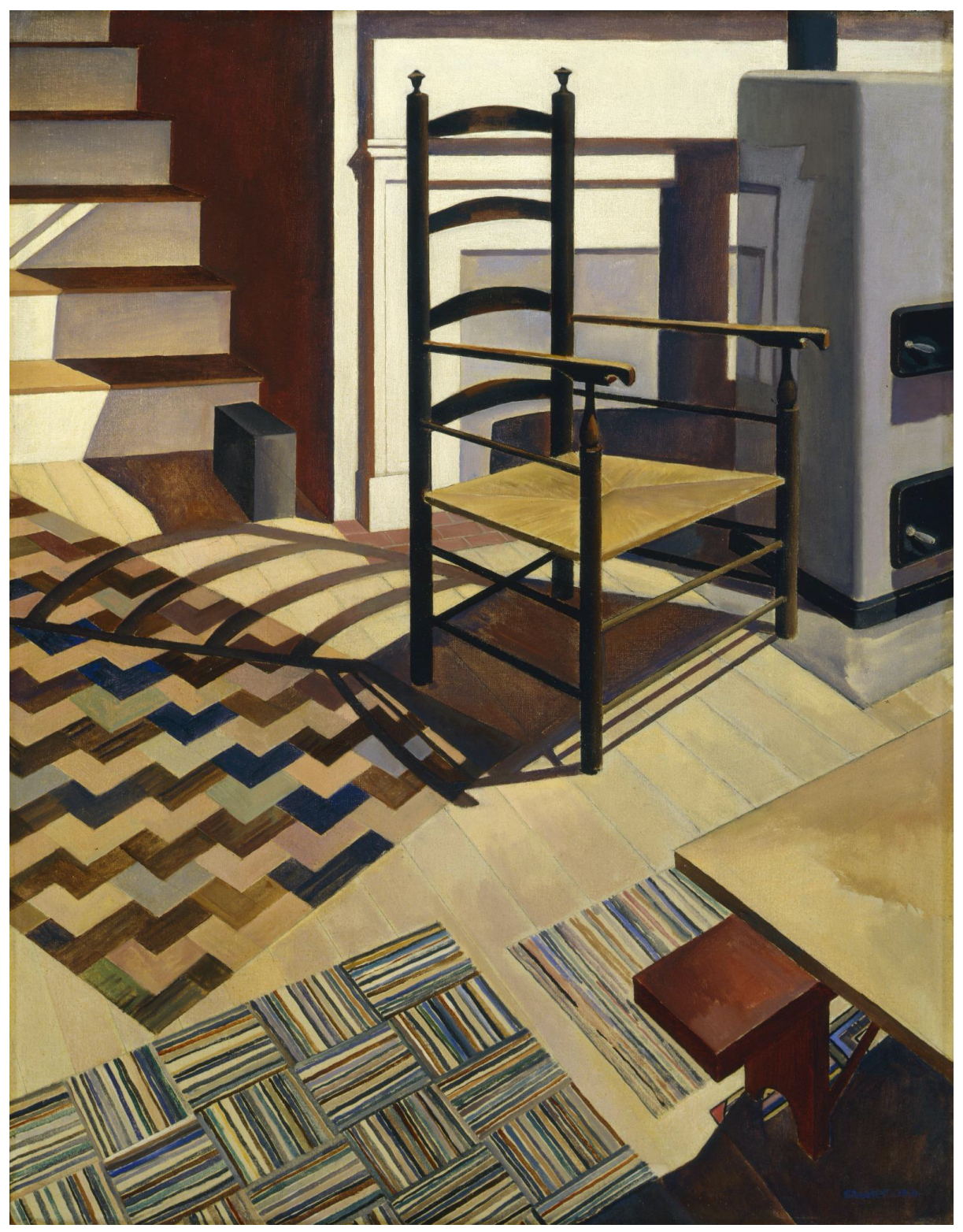

Note. From File:Charles Sheeler - Home, Sweet Home - 45.455 - Detroit Institute of Arts.jpg Wikimedia Commons, n.d. (https: / / commons.wikimedia.org/wiki / File:Charles_Sheeler__Home,_Sweet_Home_-_45.455_-_Detroit_Institute_of_Arts.jpg). In the public domain. 
Figure 3

Prototype of Student Project - Artwork with AR Overlay \# 1

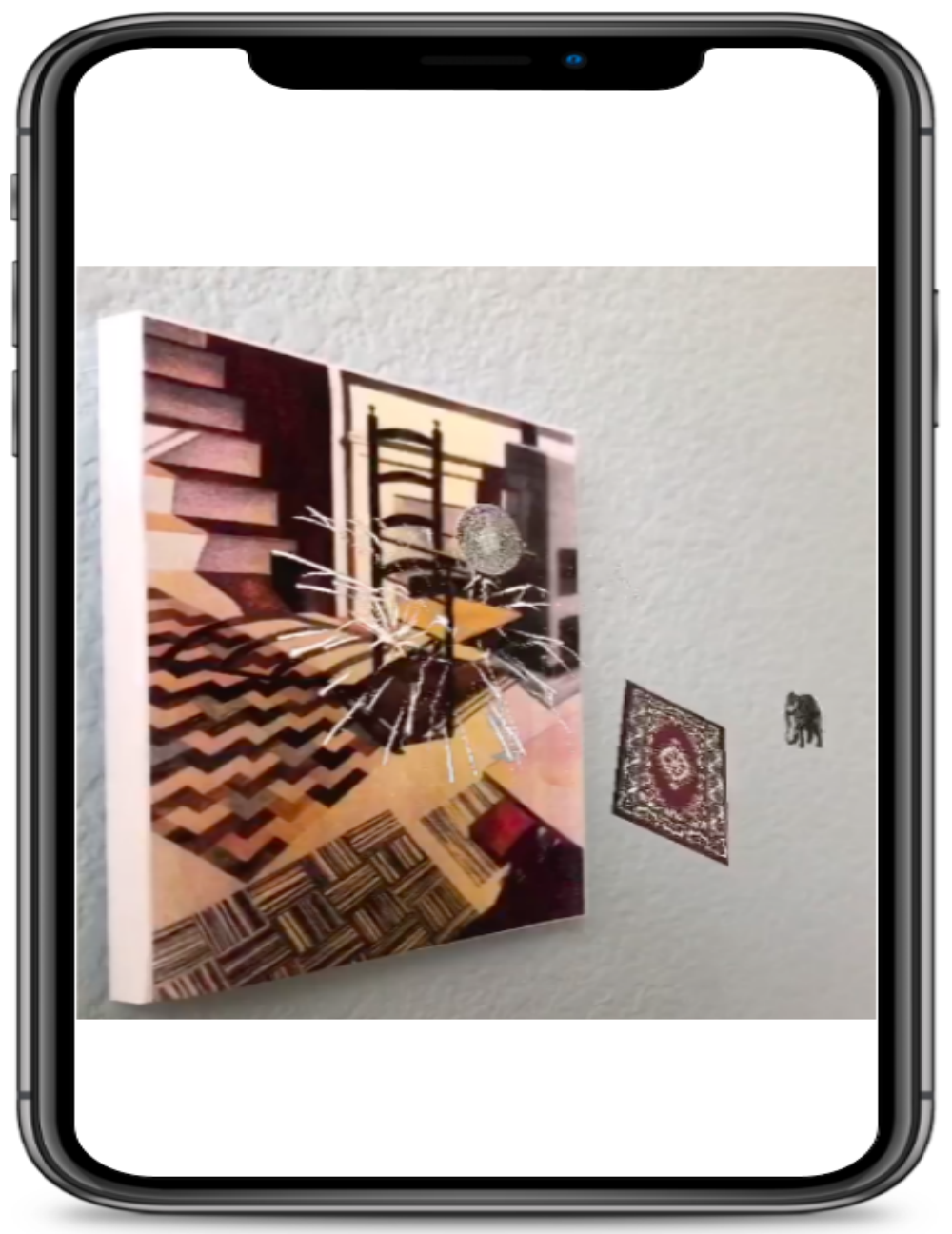


Figure 4

Prototype of Student Project - Artwork with AR Overlay \#2

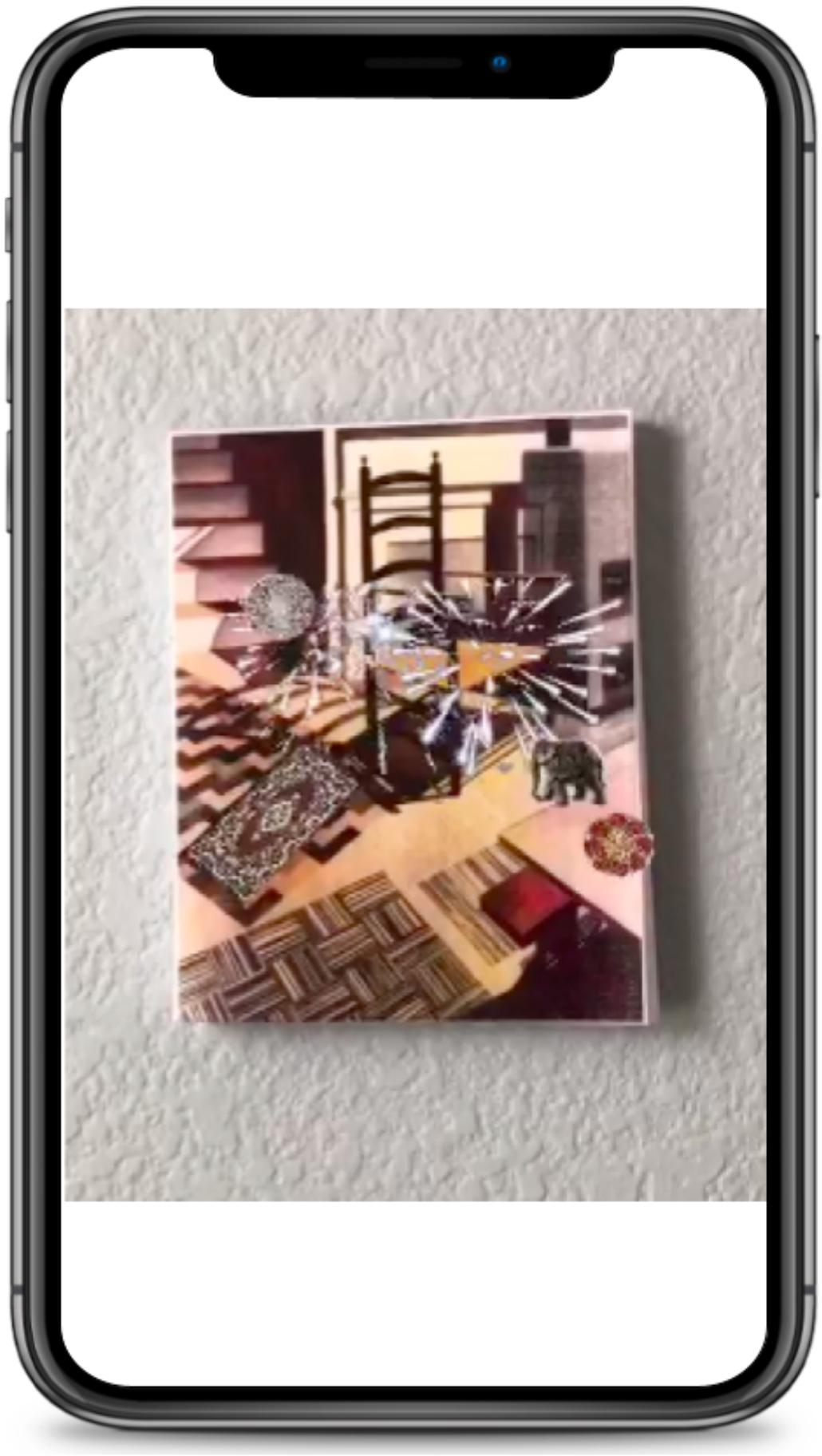


In this essay, we asserted that youth can be empowered to interrogate and critique their world through the use of digital technology and artifact construction and showcased the ARt of Inequality curriculum as an illustrative example. Specifically, the purpose of our curriculum is to bridge the racial and socioeconomic gap in digital art, activism education and museum curation. Students would not only gain a deeper understanding of existing social justice issues, but they would also learn to address them in creative and meaningful ways. We recognize that our proposed curriculum is just one of many possible approaches to achieving these aims, and invite readers to consider how learning experiences that occur in other educational settings or incorporate digital technologies with different affordances for creative expression might support youth empowerment. Through the creation and museum exhibition of personally relevant digital artifacts that address social justice issues, youth can utilize technology to question dominant narratives and experience using art as a vehicle for social change within their communities.

\section{Acknowledgements}

The authors thank Paulo Blikstein, Chelsea Villareal, and Fabio Campos, as well as Sejin Park and multiple unnamed museum educators, public school art teachers, and high school students in New York City.

\section{Author Note}

Correspondence concerning this article can be addressed to Anisa Bora. Email: ayb2119@tc.columbia.edu

Anisa Bora is a Computing in Education MA student in the Communication, Media, and Learning Technologies Design program at Teachers College, Columbia University. She previously served as a curriculum designer and educator for informal STEM education programs. Her interests include project-based learning, curriculum design, inclusive teaching, and technology in education.

Grace J. Choi is a Master's student in Educational Computing program within the Communication, Media, and Learning Technologies Design Program at Teachers College, Columbia University. Her research interests include maker education, YPAR, critical race literacy, and pedagogical methodologies in museums, historical societies and heritage sites, as well as adult education.

Thomonique Moore is an Instructional Technology and Media MA student in the Communication, Media, and Learning Technologies Design Program at Teachers College, Columbia University. She is interested in exploring how digital tools, media-making, and Youth Participatory Action Research (Y-PAR) can be used to promote culturally relevant pedagogies and critical race literacy in classrooms.

Rongwei Tang is a Master's student in Anthropology and Education at Teachers College, Columbia University. Her research interests include media literacy education, youth's digital practices, online activities and education technology.

Yiming Zheng is an Instructional Technology and Media MA student in the Communication, Media, and Learning Technologies Design Program at Teachers College, Columbia University. She is interested in researching how social organizations such as schools and corporations change under

the impact of new media and technologies. 


\section{References}

Adams, J. (2001). The makings of political art. Qualitative Sociology, 24(3), 311-348. https: / / doi.org/10.1023 / A:1010686807291

Blikstein, P. (2008). Travels in Troy with Freire: Technology as an agent of emancipation. In P. Noguera \& C. A. Torres (Eds.), Social Justice Education for Teachers: Paulo Freire and the possible dream (pp. 205-244). Rotterdam, Netherlands: Sense.

Bower, M., Howe, C., McCredie, N., Robinson, A., \& Grover, D. (2014). Augmented Reality in education - cases, places and potentials. Educational Media International, 51(1), 1-15. https: / / doi.org/10.1080/09523987.2014.889400

Edwards, E., Gosden, C., \& Phillips, R. (Eds.). (2006). Sensible objects: Colonialism, museums and material culture (1st. ed., Vol. 5). Berg.

Freire, P. (2005). Pedagogy of the oppressed (MB Ramos, Trans.). Continuum. (Original work published 1970)

Holbert, N., Dando, M., \& Correa, I. (2020). Afrofuturism as critical constructionist design: Building futures from the past and present. Learning, Media and Technology, 45(4), 328-344. https: / / doi.org/10.1080/17439884.2020.1754237

Moorhouse, N., \& Dieck, T. MC, \& Jung, T.(2019). An experiential view to children learning in museums with augmented reality. Museum Management and Curatorship, 34(4), 1-17. https: / doi.org/10.1080/09647775.2019.1578991

Ng, W., Ware, S. M., \& Greenberg, A. (2017). Activating diversity and inclusion: A blueprint for museum educators as allies and change makers. Journal of Museum Education, 42(2), 142-154. https: / / doi.org/10.1080/10598650.2017.1306664

Papert, S. (1988). A critique of technocentrism in thinking about the school of the future. Children in the Information Age (pp. 3-18). https://doi.org/10.1016/b978-0-08036464-3.50006-5

Ryan, H. E. (2015). Affect's effects: Considering art-activism and the 2001 crisis in Argentina. Social Movement Studies, 14(1), 42-57. https: / / doi.org/10.1080/14742837.2014.944893

Sheeler, C. (1931). Home, Sweet Home [Painting]. Detroit Institute of Arts, Detroit, MI, United States. https://www.dia.org/art/collection/object/home-sweet-home61185.Wikimedia.org.

https: / / commons.wikimedia.org/wiki/File:Charles_Sheeler_-

_Home,_Sweet_Home_-_45.455_-_Detroit_Institute_of_Arts.jpg

Srikanth, A. (2021, February 4). How AR is bringing Black history to life for middle schoolers across America. The Hill. Retrieved April 24, 2021, from https: / thehill.com/ changing-america/ enrichment/ education/536562-how-vris-bringing-black-history-to-life-for-middle

Thanapornsangsuth, S., \& Holbert, N. (2020). Culturally relevant constructionist design: Exploring the role of community in identity development. Information and Learning Sciences, 121(11-12), 847-867._https: / / doi.org/10.1108/ILS-02-2020-0024 
Weibel, P. (Ed.). (2015). Global activism: Art and conflict in the 21st century. ZKM- Center for Art and Media.

Wilson, K. (2011). Ambivalence, Irony, and Americana: Charles Sheeler's "American Interiors". Winterthur Portfolio, 45(4), 249-276. https: / / doi.org/10.1086/663158 